OPEN ACCESS

Edited by:

Bruce Campbell,

University of Melbourne,

Australia

Reviewed by:

Christian H. Nolte,

Charité - Universitätsmedizin

Berlin, Germany

Benjamin B. Clissold,

Monash University, Australia

*Correspondence:

Mahesh V. Jayaraman mjayaraman@lifespan.org

Specialty section:

This article was submitted to Stroke,

a section of the journal

Frontiers in Neurology

Received: 26 August 2017

Accepted: 11 December 2017

Published: 19 January 2018

Citation:

Jayaraman MV and McTaggart RA (2018) Endovascular Treatment of

Anterior Circulation Large Vessel

Occlusion in the Elderly.

Front. Neurol. 8:713.

doi: 10.3389/fneur.2017.00713

\section{Endovascular Treatment of Anterior Circulation Large Vessel Occlusion in the Elderly}

\author{
Mahesh V. Jayaraman ${ }^{1,2,3,4 *}$ and Ryan A. McTaggart ${ }^{1,2,3,4}$ \\ ${ }^{1}$ Department of Diagnostic Imaging, Warren Alpert School of Medicine at Brown University, Providence, Rl, United States, \\ ${ }^{2}$ Department of Neurology, Warren Alpert School of Medicine at Brown University, Providence, Rl, United States, \\ ${ }^{3}$ Department of Neurosurgery, Warren Alpert School of Medicine at Brown University, Providence, Rl, United States, \\ ${ }^{4}$ The Norman Prince Neuroscience Institute, Rhode Island Hospital, Providence, Rl, United States
}

Endovascular treatment of anterior circulation large vessel occlusion in the elderly population presents special challenges and opportunities. In this review, we discuss the published literature regarding thrombectomy in elderly patients and also discuss specific issues related to treatment in this patient population. In summary, while the overall outcomes following thrombectomy in elderly patients are worse than following thrombectomy in younger patients, there appears to be a similar benefit as in young patients. While there are challenges with successfully delivering thrombectomy in older patients, age alone should not be an independent exclusion from thrombectomy.

Keywords: stroke, large vessel occlusion, thrombectomy, elderly, intervention

\section{INTRODUCTION}

Acute ischemic stroke caused by large vessel occlusion (LVO) in the anterior circulation is the leading cause of adult disability in the developed world. Until recently, the only therapy proven to improve outcomes for all ischemic stroke patients was the intravenous (IV) administration of tissue plasminogen activator (tPA), which can be administered up to $4.5 \mathrm{~h}$ from the onset of symptoms or when the patient was last known normal. Unfortunately, those strokes caused by occlusion of the large intracranial vessels, such as the internal carotid artery (ICA) and proximal middle cerebral artery (MCA), had low rates of response to IV tPA, and subsequently, poor outcomes (1).

The next revolution in stroke began in 2015, when five randomized trials all showed that rapid mechanical thrombectomy, primarily using stent-retriever devices, significantly improves outcomes in anterior circulation (ICA and MCA) LVO stroke patients (2-7). Even more striking was the absolute magnitude of benefit, with a number needed to treat as low as 2.5 to have one patient be less disabled $(8,9)$. Few, if any, therapies in medicine can approach that level of benefit. Recently, the benefit of thrombectomy has been shown to extend out to $24 \mathrm{~h}$, in patients with a favorable imaging profile (10).

The application of this highly effective therapy to the older population presents unique challenges, however. The incidence of stroke is higher in the older population (11), and it is likely that we will encounter this issue with increasing frequency in daily clinical practice. In this review, we will highlight these issues in the aging population. We will focus on LVO in the anterior circulation, predominantly in the ICA or MCA. 


\section{CURRENT LITERATURE-IS THERE A BENEFIT FOR THE ELDERLY?}

\section{Single Armed Trials of Treatment}

Several single and multicenter case series have been published examining the question of whether there is a benefit of treatment in the elderly (12-16). Sallustio and colleagues compared the outcomes between patients younger than 80 and those 80 and older, in a series of 239 patients. They found no significant differences in clinical outcomes at 90 days with $34.3 \%$ of young patients achieving independence (modified Rankin score 0-2) compared with $30.6 \%$ of the older group (14). While overall mortality was higher in the older cohort ( 40.3 vs. $29.2 \%$ ), the neurologic related mortality was lower in the older group (14.5 vs. $21 \%$ ), suggesting a larger number of preexisting comorbidities. By contrast, in the multicenter NASA registry, only $27.3 \%$ of patients 80 or older achieved independence at 90 days, compared with $45.4 \%$ for the younger group (17), suggesting worse outcomes in the older group.

Singer evaluated 362 patients in the multicenter ENDOSTROKE registry and showed a significant dependence of age on outcomes. Only $17 \%$ of patients in the oldest quartile (77-94 years old) achieved independence at 90 days, compared with $37 \%$ in those $69-67$ years old, $47 \%$ in the 57 - to 68 -year-old group, and $60 \%$ in those younger than 57 . In addition, there was an increasing rate of poor outcome despite recanalization with age, reaching 53\% in the oldest age group. They suggested that medical comorbidities, procedural issues such as tortuous anatomy, the use of general anesthesia, and impaired collaterals all played a role in these observed poor outcomes (18). Shi also showed that in a pooled analysis of the MERCI, TREVO, and TREVO 2 trials, increasing age was a strong predictor of poor outcome (19).

Khan and colleagues examined the impact of treatment on nonagenarians, compared with the younger cohort (12). They did show a much lower rate of good outcome in the nonagenarians, with only $11.1 \% \mathrm{mRs} 0-2$ at 90 days vs. $48 \%$ in the younger cohort, but they acknowledge a higher baseline level of disability in the older group and suggest that there may be a role for therapy in nonagenarians with good prestroke functional status. Recently, Imahori et al. examined the benefit of complete recanalization (TICI 3) vs. incomplete recanalization (TICI $0-2 \mathrm{~b}$ ) in a series of 80 patients, dichotomized by age $\geq 80$ vs. $<80$ years (15). They found that independence at 90 days (mRs $0-2$ ) was $65 \%$ in the older cohort and $68 \%$ in the younger cohort, when TICI 3 recanalization was achieved, and 21 vs. $45 \%$ for TICI $0-2 b$ in the older and younger cohorts, respectively. This would suggest that perhaps, with complete recanalization, older patients can achieve similar rates of functional independence.

A meta-analysis by Duffis examined this specific issue and found higher rates of symptomatic intracranial hemorrhage and lower rates of good functional outcome in patients older than 80 (20). However, while they included a total of 8 studies with 2,279 patients, there was extreme heterogeneity in the endovascular treatment methods, and most patients were not treated with modern stent-retriever or aspiration devices.
In summary, most single armed trials of thrombectomy in anterior circulation stroke show worse outcomes with older age as compared with younger cohorts.

\section{Randomized Trials of Thrombectomy}

However, all of the aforementioned series were reporting outcomes of patients treated with thrombectomy. What about randomization compared with medical therapy alone? Among the current generation of randomized thrombectomy trials, prespecified analysis based on an age threshold shows significant benefit in older subgroups in the ESCAPE and MR CLEAN trials (divided as 80 years or older vs. younger) and in the SWIFT-PRIME (divided as 70 years or older vs. younger) trial, with no heterogeneity of benefit. In the REVASCAT trial, there was not a difference between medical and endovascular therapy in the older subgroup, but this difference was not statistically significant. These results are summarized in Table $\mathbf{1}$. The sample size in EXTEND-IA was too small to allow for such an analysis. In HERMES, the pooled, patient level meta-analysis of these five trials, there was no difference in the benefit of thrombectomy across the entire age spectrum using a mixed methods linear regression (8). That is to say, the older patients did worse than the younger patients regardless of treatment modality, but the same degree of benefit of endovascular therapy was present throughout the age spectrum. In addition, when divided into subgroups, the adjusted common odds ratio was not significantly different among the age 50-59, 60-69, 70-79, and 80+ groups, with $218,333,371$, and 198 patients in those groups, respectively. Similarly, even in the 6-24 h time window, the DAWN trial showed similar benefit to those less than 80 vs. 80 and older, with odds ratios of 1.9 and 2.3 , respectively, for benefit with thrombectomy (10).

In summary, while older patients may have worse outcomes overall, there is no heterogeneity of treatment effect seen by age. Thrombectomy is just as effective in elderly patients as

TABLE 1 | Summary of outcomes in older patients in seven randomized trials of modern endovascular stroke thrombectomy (primarily using stent-retriever devices).

\begin{tabular}{|c|c|c|c|}
\hline Trial & Patients & $\begin{array}{l}\text { Odds ratio } \\
\text { for favorable } \\
\text { outcomes with } \\
\text { thrombectomy }\end{array}$ & $\begin{array}{l}\text { Independence at } 90 \text { days } \\
\text { (mRs 0-2) in older } \\
\text { and younger groups; } \\
\text { endovascular vs. control }\end{array}$ \\
\hline MR CLEAN (6) & 500 & $\begin{array}{l}\text { Age }<80 \text { years: } 1.6 \\
\text { Age } \geq 80 \text { years: } 3.2\end{array}$ & Not reported \\
\hline ESCAPE (4) & 316 & $\begin{array}{l}\text { Age } \leq 80 \text { years: } 3.0 \\
\text { Age }>80 \text { years: } 2.7\end{array}$ & $\begin{array}{l}\text { Age } \leq 80 \text { years: } 59.3 \text { vs. } \\
33.4 \% \\
\text { Age }>80 \text { years: } 37 \text { vs. } 18 \%\end{array}$ \\
\hline REVASCAT (3) & 206 & $\begin{array}{l}\text { Age } \leq 70 \text { years: } 2.5 \\
\text { Age }>70 \text { years: } 0.9\end{array}$ & $\begin{array}{l}\text { Age } \leq 70 \text { years: } 52.5 \text { vs. } \\
23.3 \% \\
\text { Age }>70 \text { years: } 30.9 \text { vs. } \\
34.9 \%\end{array}$ \\
\hline SWIFT-PRIME (2) & 191 & $\begin{array}{l}\text { Age }<70 \text { years: } 1.67 \\
\text { Age } \geq 70 \text { years: } 1.78\end{array}$ & $\begin{array}{l}\text { Age }<70 \text { years: } 65 \text { vs. } 40 \% \\
\text { Age } \geq 70 \text { years: } 54 \text { vs. } 31 \%\end{array}$ \\
\hline THRACE (7) & 402 & $\begin{array}{l}\text { Age }<70 \text { years: } 1.6 \\
\text { Age } \geq 70 \text { years: } 1.5\end{array}$ & Not reported \\
\hline DAWN (10) & 206 & $\begin{array}{l}\text { Age }<80 \text { years: } 1.9 \\
\text { Age } \geq 80 \text { years: } 2.3\end{array}$ & $\begin{array}{l}\text { Age }<80 \text { years: } 54 \text { vs. } 17 \% \\
\text { Age } \geq 80 \text { years: } 32 \text { vs. } 4 \%\end{array}$ \\
\hline
\end{tabular}


it is in younger ones. In addition, the outcomes with medical therapy alone are dismal in older patients, and rapid, successful thrombectomy may by the best chance the older patients have at a favorable outcome.

\section{Preprocedure: Making the Treatment Decision}

Ultimately, deciding to take the patient to the angiography suite for thrombectomy means that the treating team feels the procedure is likely to improve the patient's chance of meaningful neurologic recovery. In the preprocedure time period, this is dependent on the patient's baseline functional status, as well as the status of the brain tissue, as assessed by brain imaging.

Almost all the patients in the recent randomized trials of thrombectomy were required to be functionally independent for enrollment, typically defined as modified Rankin scale score of 0 or 1 . As such, in patients with preexisting disability, randomized data comparing the outcomes with thrombectomy vs. best medical therapy is lacking. Elderly patients may have a higher rate of preexisting disability, which can make the treatment decision more difficult. Pohjasvaara examined the level of pre- and poststroke disability in a cohort of 486 patients in Helsinki. They found higher levels of prestroke disability in the group aged 71-85 as compared with those aged 55-70 (21). In addition, the older group was more disabled after stroke than the younger group. Another study, compared patients older or younger than 75 and found that indeed the older group had higher prestroke levels of disability, and overall higher mortality after stroke (22). In series of IV thrombolysis in patients with preexisting disability, it has been shown that while the overall mortality is higher, the likelihood of good outcome was not influenced by previous dependency (23). Those authors suggested withholding thrombolysis in patients with preexisting disability might not be justified. Similarly, Leker and colleagues showed that while the overall outcomes following anterior circulation thrombectomy are worse in those with preexisting disability, there were some who were able to maintain their prestroke level of disability, and as such, those with moderate disability should not be excluded from thrombectomy (24). Treatment guidelines from the American Heart Association consider treatment of patients with preexisting disability as "may be reasonable," but suggest additional data would be helpful (25).

There can be additional difficulties in establishing a functional baseline in patients who come from a non-home living situation. Patients may be in assisted living facilities requiring varying amounts of assistance with activities of daily living. However, in the time critical period between hospital arrival and treatment decision, it may be difficult to elucidate how functional the patient was prestroke, especially when family is not available to provide additional history. These additional items should not delay thrombectomy, but may be difficult to obtain in a timely fashion. It is also possible that patient age may play a role in determining if a patient should be transferred from a non-thrombectomy capable center to one where they can be treated, although data are lacking in this regard.
In summary, preexisting disability is more common in elderly patients and would have excluded them from most randomized trials of thrombectomy. While preexisting disability is not an absolute contraindication to treatment, the team evaluating the patient should do their best to assess prestroke functional status and make an individualized decision in elderly patients with preexisting disability.

\section{Preprocedure: Imaging Issues}

Baseline brain parenchymal imaging (with non-contrast CT) and vessel imaging [with CT angiography (CTA)] should be the minimum standard on all stroke patients, regardless of severity (26). The degree of completed infarction (infarct core) on NCCT is often measured using the Alberta Stroke program early CT score. Core infarct estimation can also be made with assessment of the degree of collateral filling beyond the occlusion on CTA (CTA-Collateral Score), using dynamic CT perfusion, or using diffusion-weighted imaging (DWI) sequences on MRI. With respect to vascular imaging, older patients may have diminished cardiac output, which may result in suboptimal bolus acquisition on CTA. The use of multiphase CTA, with two additional scans through the brain, may ameliorate some of those issues by allowing for additional imaging in those patients with poor cardiac output (27).

Preexisting leukoaraiosis, typically more prevalent in an older patient, has been associated with worse outcomes after thrombectomy as well (28). In addition, leukoaraiosis may lead to overestimation of infarct core in the white matter on CT perfusion using relative cerebral blood flow thresholds (29). Agarwal and colleagues showed in a small series of patients undergoing whole brain CT perfusion that age was negatively correlated with normalized lesion and penumbral volume, but not core volume (30). These changes occurred despite an increased collateral response in older patients and suggest future study is warranted into this age-dependent response to ischemia.

Some series have suggested an age-dependent threshold may be accurate for the degree of baseline infarct beyond which endovascular thrombectomy is unlikely to help the patient (31). A recent series trichotomized patients into age groups, with the oldest group being older than 75 (32). Not surprisingly, the elderly patients had favorable outcomes in $50 \%$ of cases with minimal baseline infarction (DWI lesion volume $<5 \mathrm{~mL}$ ), as compared with 80 and $91 \%$ of patients with similar lesion volumes in the age 66-75 and age less than 66 cohorts, respectively. More profound, however, was the difference in clinical outcomes when baseline DWI lesion was more than $5 \mathrm{~mL}$, where only $19 \%$ of elderly patients achieved independence, compared with 44 and 56\%, respectively. This would indeed suggest an age-dependent relationship between baseline infarct and likelihood of a good outcome. The DAWN study also used this concept, with an age-dependent infract core threshold, excluding patients older than 80 if they had a core infarct on CT perfusion or DWI of larger than $21 \mathrm{~mL}$, but allowing infarct cores up to a volume of $50 \mathrm{~mL}$ in younger patients.

In summary, when evaluating pretreatment imaging one may need to take patient age into account, especially as it 
pertains to the evaluation of core infarct volume, regardless of modality.

\section{STARTING THE PROCEDURE: ANESTHESIA AND PATIENT COOPERATION}

In the HERMES dataset, it was beneficial to use conscious sedation or local anesthesia as opposed to general anesthesia. This effect may be more so in the elderly population, as there are additional risks from anesthesia. Some recent studies, however, have suggested no difference in outcomes between sedation and general anesthesia $(33,34)$. However, the vast majority of the patients in AnStroke and SIESTA were younger. There can be greater blood pressure decreases in patients under general anesthesia (35), which can be detrimental to collateral flow. Patient cooperation, if the patient is being treated with sedation or local anesthesia, may also be an issue, especially if the patients have some level of preexisting cognitive dysfunction. The use of benzodiazepines, typically diazepam or midazolam is common during procedural sedation. Scholer showed an inverse correlation between age and the dose of both diazepam and midazolam needed to successfully perform endoscopy (36). Interestingly, they showed an even steeper decline in the dose of midazolam needed as compared with diazepam as patients aged.

When using propofol for procedural sedation during endoscopy, Heuss showed that while elderly patients (age $>70$ years) had slightly higher rates of short periods of oxygen desaturation below $90 \%$, and an overall decrease in oxygen saturation below $5 \%$, especially in those above the age of 85 , but they felt that overall, propofol is safe for sedation in the elderly (37).

To summarize, while no study has demonstrated a benefit to using general anesthesia over conscious sedation, nor are there substantial data evaluating the relationship of mode of anesthesia with outcomes in older patients undergoing endovascular stroke thrombectomy, it may be preferable in patients of all ages to use conscious sedation whenever possible.

\section{Intraprocedure}

Intraprocedurally, elderly patients pose anatomic challenges, primarily due to greater tortuosity of their vasculature. Placement of the large bore guiding catheters, including balloon guide catheters, can be more difficult in the elderly population. In extreme cases, direct carotid puncture can be performed, but also likely introduces additional risk. In the NASA registry, procedure times were slightly longer in the elderly cohort, which may be on the basis of the arterial anatomy (17). Imahori also showed longer revascularization times in older patients ( $45 \mathrm{vs.} 31 \mathrm{~min}$ ) in their single center series (15). In contradistinction, Sallustio showed slightly shorter recanalization times in older patients (60 vs. $78.5 \mathrm{~min}$ ) (14).

\section{Postprocedural Care}

Post revascularization, critical issues include the need to closely follow the patient's neurologic exam as well as hemodynamic parameters to potentially minimize the likelihood of intracranial hemorrhage. In elderly patients treated under general anesthesia, postoperative delirium may be common and can cloud the neurologic examination (38).

Patients with higher baseline systolic blood pressure have higher rates of symptomatic intracranial hemorrhage after systemic thrombolysis. As such, current recommendations are to maintain blood pressure below 185 systolic and 110 diastolic following systemic thrombolysis $(39,40)$. While the optimal target blood pressures after thrombectomy are unknown, a recent retrospective analysis showed that after TICI $2 \mathrm{~b}$ or greater recanalization, patients in whom the systolic blood pressure was kept below $160 \mathrm{mmHg}$ had better clinical outcomes than those with higher blood pressures (41).

\section{FUTURE DIRECTIONS AND UNANSWERED QUESTIONS}

Among the main unanswered questions, regarding thrombectomy is whether our systems of care are sufficiently well enough organized to provide access to this therapy. Should patients be routed in the field to endovascular capable centers, bypassing closer, non-endovascular capable centers? $(42,43)$. If so, would there be a bias on the part of EMS to preferentially divert younger patients and not older ones? If such diversion is to occur, is there a differential accuracy of field severity screening tools in younger vs. older patients? One recent study suggests in patients with leukoariosis, severity scores may be less accurate for detection of LVO (44). In addition, a newer trial (NCT02930018) is examining whether a novel neuroprotective agent can improve outcomes in patients undergoing thrombectomy for ICA or M1 occlusions. Will this (or other agents), if shown to be beneficial, have the same effectiveness in older patients?

\section{SUMMARY}

In summary, while the overall benefit of thrombectomy is similar in older and younger patients, elderly patients are less likely to achieve functional independence. This may be on the basis of slightly higher levels of prestroke disability, decreased functional reserve, and diminished tolerance to larger core infarcts before recanalization. Age alone should not exclude patients from thrombectomy, but the treating team should be aware of and prepared for factors, which make treatment in this group potentially more challenging.

\section{AUTHOR CONTRIBUTIONS}

Both authors contributed to literature review, manuscript revision, and final review. 


\section{REFERENCES}

1. Lima FO, Furie KL, Silva GS, Lev MH, Camargo EC, Singhal AB, et al. Prognosis of untreated strokes due to anterior circulation proximal intracranial arterial occlusions detected by use of computed tomography angiography. JAMA Neurol (2014) 71:151-7. doi:10.1001/jamaneurol.2013.5007

2. Saver JL, Goyal M, Bonafe A, Diener HC, Levy EI, Pereira VM, et al. Stentretriever thrombectomy after intravenous t-PA vs. t-PA alone in stroke. $N$ Engl $J$ Med (2015) 372:2285-95. doi:10.1056/NEJMoa1415061

3. Jovin TG, Chamorro A, Cobo E, de Miquel MA, Molina CA, Rovira A, et al. Thrombectomy within 8 hours after symptom onset in ischemic stroke. N Engl J Med (2015) 372:2296-306. doi:10.1056/NEJMoa1503780

4. Goyal M, Demchuk AM, Menon BK, Eesa M, Rempel JL, Thornton J, et al. Randomized assessment of rapid endovascular treatment of ischemic stroke. N Engl J Med (2015) 372:1019-30. doi:10.1056/NEJMoa1414905

5. Campbell BC, Mitchell PJ, Kleinig TJ, Dewey HM, Churilov L, Yassi N, et al. Endovascular therapy for ischemic stroke with perfusion-imaging selection. N Engl J Med (2015) 372:1009-18. doi:10.1056/NEJMoa1414792

6. Berkhemer OA, Fransen PS, Beumer D, van den Berg LA, Lingsma HF, Yoo AJ, et al. A randomized trial of intraarterial treatment for acute ischemic stroke. N Engl J Med (2015) 372:11-20. doi:10.1056/NEJMoa1411587

7. Bracard S, Ducrocq X, Mas JL, Soudant M, Oppenheim C, Moulin T, et al. Mechanical thrombectomy after intravenous alteplase versus alteplase alone after stroke (THRACE): a randomised controlled trial. Lancet Neurol (2016) 15:1138-47. doi:10.1016/S1474-4422(16)30177-6

8. Goyal M, Menon BK, van Zwam WH, Dippel DW, Mitchell PJ, Demchuk AM, et al. Endovascular thrombectomy after large-vessel ischaemic stroke: a meta-analysis of individual patient data from five randomised trials. Lancet (2016) 387:1723-31. doi:10.1016/S0140-6736(16)00163-X

9. Saver JL, Goyal M, van der Lugt A, Menon BK, Majoie CB, Dippel DW, et al. Time to treatment with endovascular thrombectomy and outcomes from ischemic stroke: a meta-analysis. JAMA (2016) 316:1279-88. doi:10.1001/ jama.2016.13647

10. Nogueira RG, Jadhav AP, Haussen DC, Bonafe A, Budzik RF, Bhuva P, et al. Thrombectomy 6 to 24 hours after stroke with a mismatch between deficit and infarct. N Engl J Med (2017). doi:10.1056/NEJMoa1706442

11. Ovbiagele B, Nguyen-Huynh MN. Stroke epidemiology: advancing our understanding of disease mechanism and therapy. Neurotherapeutics (2011) 8:319-29. doi:10.1007/s13311-011-0053-1

12. Khan MA, Baird GL, Miller D, Patel A, Tsekhan S, Yaghi S, et al. Endovascular treatment of acute ischemic stroke in nonagenarians compared with younger patients in a multicenter cohort. J Neurointerv Surg (2017) 9:727-31. doi:10.1136/neurintsurg-2016-012427

13. Son S, Kang DH, Hwang YH, Kim YS, Kim YW. Efficacy, safety, and clinical outcome of modern mechanical thrombectomy in elderly patients with acute ischemic stroke. Acta Neurochir (2017). doi:10.1007/s00701-017-3269-y

14. Sallustio F, Koch G, Motta C, Diomedi M, Alemseged F, D’Agostino VC, et al. Efficacy and safety of mechanical thrombectomy in older adults with acute ischemic stoke. JAm Geriatr Soc (2017) 65:1816-20. doi:10.1111/ jgs.14909

15. Imahori $\mathrm{T}$, Tanaka $\mathrm{K}$, Arai A, Shiomi R, Fujiwara D, Mori $\mathrm{T}$, et al. Mechanical thrombectomy for acute ischemic stroke patients aged 80 years or older. J Stroke Cerebrovasc Dis (2017) 26:2793-9. doi:10.1016/j. jstrokecerebrovasdis.2017.06.060

16. Slater LA, Coutinho JM, Gralla J, Nogueira RG, Bonafe A, Davalos A, et al. TICI and age: what's the score? AJNR Am J Neuroradiol (2016) 37:838-43. doi:10.3174/ajnr.A4618

17. Castonguay AC, Zaidat OO, Novakovic R, Nguyen TN, Taqi MA, Gupta R, et al. Influence of age on clinical and revascularization outcomes in the North American Solitaire Stent-Retriever Acute Stroke Registry. Stroke (2014) 45:3631-6. doi:10.1161/STROKEAHA.114.006487

18. Singer OC, Haring HP, Trenkler J, Nolte CH, Bohner G, Reich A, et al. Age dependency of successful recanalization in anterior circulation stroke: the ENDOSTROKE study. Cerebrovasc Dis (2013) 36:437-45. doi:10.1159/ 000356213

19. Shi ZS, Liebeskind DS, Xiang B, Ge SG, Feng L, Albers GW, et al. Predictors of functional dependence despite successful revascularization in large-vessel occlusion strokes. Stroke (2014) 45:1977-84. doi:10.1161/ STROKEAHA.114.005603
20. Duffis EJ, He W, Prestigiacomo CJ, Gandhi CD. Endovascular treatment for acute ischemic stroke in octogenarians compared with younger patients: a meta-analysis. Int J Stroke (2014) 9:308-12. doi:10.1111/ijs.12098

21. Pohjasvaara T, Erkinjuntti T, Vataja R, Kaste M. Comparison of stroke features and disability in daily life in patients with ischemic stroke aged 55 to 70 and 71 to 85 years. Stroke (1997) 28:729-35. doi:10.1161/01.STR.28.4.729

22. Sharma JC, Fletcher S, Vassallo M. Strokes in the elderly - higher acute and 3-month mortality - an explanation. Cerebrovasc Dis (1999) 9:2-9. doi:10.1159/000015889

23. Gensicke H, Strbian D, Zinkstok SM, Scheitz JF, Bill O, Hametner C, et al. Intravenous thrombolysis in patients dependent on the daily help of others before stroke. Stroke (2016) 47:450-6. doi:10.1161/STROKEAHA. 115.011674

24. Leker RR, Gavriliuc P, Yaghmour NE, Gomori JM, Cohen JE. Increased risk for unfavorable outcome in patients with pre-existing disability undergoing endovascular therapy. J Stroke Cerebrovasc Dis (2018) 27(1):92-6. doi:10.1016/j.jstrokecerebrovasdis.2017.08.007

25. Powers WJ, Derdeyn CP, Biller J, Coffey CS, Hoh BL, Jauch EC, et al. 2015 American Heart Association/American Stroke Association focused update of the 2013 guidelines for the early management of patients with acute ischemic stroke regarding endovascular treatment: a guideline for healthcare professionals from the American Heart Association/American Stroke Association. Stroke (2015) 46:3020-35. doi:10.1161/STR.0000000000000074

26. Turc G, Maier B, Naggara O, Seners P, Isabel C, Tisserand M, et al. Clinical scales do not reliably identify acute ischemic stroke patients with large-artery occlusion. Stroke (2016) 47:1466-72. doi:10.1161/STROKEAHA. 116.013144

27. Menon BK, d'Esterre CD, Qazi EM, Almekhlafi M, Hahn L, Demchuk AM, et al. Multiphase CT angiography: a new tool for the imaging triage of patients with acute ischemic stroke. Radiology (2015) 275:510-20. doi:10.1148/ radiol.15142256

28. Gilberti N, Gamba M, Premi E, Costa A, Vergani V, Delrio I, et al. Leukoaraiosis is a predictor of futile recanalization in acute ischemic stroke. J Neurol (2017) 264:448-52. doi:10.1007/s00415-016-8366-y

29. Campbell BC, Christensen S, Levi CR, Desmond PM, Donnan GA, Davis SM, et al. Cerebral blood flow is the optimal CT perfusion parameter for assessing infarct core. Stroke (2011) 42:3435-40. doi:10.1161/ STROKEAHA.111.618355

30. Agarwal S, Scoffings DJ, Jones PS, Marrapu ST, Barry PJ, O’Brien EW, et al. Interaction of age with the ischaemic penumbra, leptomeningeal collateral circulation and haemodynamic variables in acute stroke: a pilot study. J Neurol Neurosurg Psychiatry (2013) 84:271-6. doi:10.1136/jnnp-2012-303258

31. Ribo M, Tomasello A, Lemus M, Rubiera M, Vert C, Flores A, et al. Maximal admission core lesion compatible with favorable outcome in acute stroke patients undergoing endovascular procedures. Stroke (2015) 46:2849-52. doi:10.1161/STROKEAHA.115.010707

32. Hwang YH, Kim YW, Kang DH, Kim YS, Liebeskind DS. Impact of baseline ischemia on outcome in older patients undergoing endovascular therapy for acute ischemic stroke. J Clin Neurol (2017) 13:162-9. doi:10.3988/jcn.2017.13.2.162

33. Lowhagen Henden P, Rentzos A, Karlsson JE, Rosengren L, Leiram B, Sundeman $\mathrm{H}$, et al. General anesthesia versus conscious sedation for endovascular treatment of acute ischemic stroke: the AnStroke trial (anesthesia during stroke). Stroke (2017) 48:1601-7. doi:10.1161/STROKEAHA.117.016554

34. Schonenberger S, Uhlmann L, Hacke W, Schieber S, Mundiyanapurath S, Purrucker JC, et al. Effect of conscious sedation vs general anesthesia on early neurological improvement among patients with ischemic stroke undergoing endovascular thrombectomy: a randomized clinical trial. JAMA (2016) 316:1986-96. doi:10.1001/jama.2016.16623

35. Mundiyanapurath S, Schonenberger S, Rosales ML, Carrilho Romeiro AM, Mohlenbruch M, Bendszus M, et al. Circulatory and respiratory parameters during acute endovascular stroke therapy in conscious sedation or general anesthesia. J Stroke Cerebrovasc Dis (2015) 24:1244-9. doi:10.1016/j. jstrokecerebrovasdis.2015.01.025

36. Scholer SG, Schafer DF, Potter JF. The effect of age on the relative potency of midazolam and diazepam for sedation in upper gastrointestinal endoscopy. J Clin Gastroenterol (1990) 12:145-7. doi:10.1097/00004836-199004000-00006

37. Heuss LT, Schnieper P, Drewe J, Pflimlin E, Beglinger C. Conscious sedation with propofol in elderly patients: a prospective evaluation. Aliment Pharmacol Ther (2003) 17:1493-501. doi:10.1046/j.1365-2036.2003.01608.x 
38. Neufeld KJ, Leoutsakos JM, Sieber FE, Wanamaker BL, Gibson Chambers JJ, Rao $\mathrm{V}$, et al. Outcomes of early delirium diagnosis after general anesthesia in the elderly. Anesth Analg (2013) 117:471-8. doi:10.1213/ ANE.0b013e3182973650

39. Jauch EC, Saver JL, Adams HP Jr, Bruno A, Connors JJ, Demaerschalk BM, et al. Guidelines for the early management of patients with acute ischemic stroke: a guideline for healthcare professionals from the American Heart Association/American Stroke Association. Stroke (2013) 44:870-947. doi:10.1161/STR.0b013e318284056a

40. Larrue V, von Kummer RR, Muller A, Bluhmki E. Risk factors for severe hemorrhagic transformation in ischemic stroke patients treated with recombinant tissue plasminogen activator: a secondary analysis of the EuropeanAustralasian Acute Stroke Study (ECASS II). Stroke (2001) 32:438-41. doi:10.1161/01.STR.32.2.438

41. Goyal N, Tsivgoulis G, Pandhi A, Chang JJ, Dillard K, Ishfaq MF, et al. Blood pressure levels post mechanical thrombectomy and outcomes in large vessel occlusion strokes. Neurology (2017) 89:540-7. doi:10.1212/ WNL.0000000000004184

42. Zhao H, Coote S, Pesavento L, Churilov L, Dewey HM, Davis SM, et al. Large vessel occlusion scales increase delivery to endovascular centers without excessive harm from misclassifications. Stroke (2017) 48:568-73. doi:10.1161/ STROKEAHA.116.016056

43. Milne MS, Holodinsky JK, Hill MD, Nygren A, Qiu C, Goyal M, et al. Drip 'n ship versus mothership for endovascular treatment: modeling the best transportation options for optimal outcomes. Stroke (2017) 48:791-4. doi:10.1161/STROKEAHA.116.015321

44. Mayasi Y, Goddeau RP Jr, Moonis M, Silver B, Jun-O'Connell AH, Puri AS, et al. Leukoaraiosis attenuates diagnostic accuracy of large-vessel occlusion scales. AJNR Am J Neuroradiol (2017). doi:10.3174/ajnr.A5473

Conflict of Interest Statement: The authors declare that the research was conducted in the absence of any commercial or financial relationships that could be construed as a potential conflict of interest.

Copyright (c) 2018 Jayaraman and McTaggart. This is an open-access article distributed under the terms of the Creative Commons Attribution License (CC BY). The use, distribution or reproduction in other forums is permitted, provided the original author(s) or licensor are credited and that the original publication in this journal is cited, in accordance with accepted academic practice. No use, distribution or reproduction is permitted which does not comply with these terms. 